\title{
Miradas multidisciplinarias en torno a la masculinidad: desafíos para la impartición de justicia
}

Multidisciplinary views around masculinity: challenges for the administration of justice

\author{
Reseña de libro \\ Book Review
}

Melissa Fernández Chagoya (2016). Miradas Multidisciplinarias en torno a la masculinidad: desafios para la impartición de justicia. Colección Género, Derecho y Justicia, Ciudad de México, Suprema Corte de Justicia de la Nación y Editorial Fontamara, 197 pp.

\section{Isabella M. Esquivel Ventura ${ }^{a}$}

\begin{abstract}
:
NO APLICA.

Keywords:

reseña

Resumen:

NO APLICA.

Palabras Clave:

review

La impartición de justicia en México ha sido históricamente un ámbito masculinizado, que reproduce y perpetúa el orden social de género de subordinación de las mujeres y lo femenino ante los hombres y lo masculino. Al respecto, Melissa Fernández Chagoya, investigadora y antropóloga feminista mexicana que nos representó de 2014 a 2017 como Experta Suplente ante el Mecanismo de Seguimiento de la Implementación de la Convención Belém Do Pará, coordina el libro Miradas multidisciplinarias en torno a la masculinidad: desafíos para la impartición de justicia, una obra necesaria para identificar y comprender el masculinismo que ha obstaculizado el acceso de las mujeres a la justicia.
\end{abstract}

Desde el propósito del libro y a lo largo de los diez capítulos que lo integran, las y los autores analizan, desde diversas disciplinas y latitudes, la impartición de justicia desde el enfoque de masculinidades. Sin embargo, más que hacer alusión a las masculinidades como las formas en que ciertos grupos de hombres experimentan y materializan la masculinidad, ponen en evidencia cómo es que la masculinidad hegemónica, su sistema de dominación y masculinismo influyen en las formas en cómo se conciben las leyes y la justicia, "que en muchas ocasiones pueden reproducir una perspectiva patriarcal que se presume - y asume- como neutral" (p. xiii).

Este abordaje es necesario para poder impulsar y dar seguimiento a la transformación de la justicia en 
favor garantizar todos los derechos humanos. Pero además de hacerlo a partir de reconocer los efectos de las desigualdades, discriminaciones y violencias en las mujeres y demás grupos en situación de vulnerabilidad, resulta necesario que también se realice a partir de identificar a la masculinidad hegemónica como causa estructural común de todos esos grupos, en tanto se trata de un modelo social idealizado que prevalece en nuestra organización sociocultural.

Para comprender la mirada masculinista ya referida, Oscar Emilio Laguna explica que "la justicia tiene mirada de varón", y no en referencia a un hombre en específico, sino a las construcciones sociales y culturales del patriarcado y la estructura jerárquica de relaciones que establece entre los sujetos en función de su aproximación o alejamiento al modelo idealizado de masculinidad (p. 1). Esto ha sido perpetuado por estructuras históricas de desigualdad de género que Joan Vendrell identifica a través de las nociones históricas occidentales de ciudadanía y derecho, con las cuales ha sido posible mantener el sistema de dominación masculina que se extiende aún a la moderna idea de derechos humanos.

Desde este punto, la impartición de justicia es cuestionada por autores como Ignacio Lozano, para afirmar que lo que se imparte en realidad en nuestro país es "injusticia", toda vez que el sistema binario de género implica, al menos, el establecimiento de un sujeto "masculino" en oposición a un sujeto "femenino", donde el primero está dotado de poder, privilegios y dividendos patriarcales que no desea soltar. Por tanto, si la justicia es impartida por los sujetos masculinos -gracias a la tradición de nociones históricas como ciudadanía y derecho aún vigentes-, su actuar dentro del sistema legal continúa privilegiando la masculinidad (p. 23). Otra característica señalada por Melissa Fernández y Mauro Vargas es la indolencia, concebida como "la incapacidad de conmoverse o sentirse afectado/a por algo; [... la] pereza, desidia e insensibilidad, muy particularmente frente al dolor" (p. 61). En el caso del sistema patriarcal de dominación masculina, se trata de la indolencia frente a las injusticias que experimentan las mujeres, los cuerpos feminizados y las identidades y experiencias que no correspondan al ideal masculino, para quienes predomina, además, la impunidad enraizada en nombre de la imparcialidad o neutralidad de la justicia.

Entre los casos más emblemáticos de esta impartición masculinista de (in)justicia en México se encuentran, lamentablemente, los feminicidios en Ciudad Juárez, retomados por algunos autores de esta obra. Jules Falquet, propone analizar los feminicidios a partir de la vinculación del sistema patriarcal con el "sistema de explotación del trabajo de las mujeres, la impunidad fomentada por el Estado, la tolerancia a la misoginia inscrita en la cultura dominante y el poder masculino en la esfera íntima” (p. 95), para reconocer cómo las lógicas presentes en otros ámbitos también participan de las barbaries ejercidas a través de los feminicidios. En este sentido, Salvador Cruz agrega que los feminicidios no se reducen a la búsqueda de justicia con quienes ejecutan los delitos, sino a toda la estructura y procesos que la posibilitan (p. 123).

Realizar este análisis de las implicaciones de la masculinidad desde su carácter estructural contribuye a comprender la magnitud de los problemas que requieren justicia, así como trascender visiones que reducen las prácticas machistas y violentas a contextos de marginación social. Para ello, Martín de la Cruz, María Teresa Garzón y Bertha Alicia Bermúdez comparten experiencias de trabajo con hombres en contextos marginados, como son algunas comunidades indígenas y situaciones de calle, para plantear la necesidad de que las intervenciones públicas y la impartición de justicia aborden los factores que se intersectan y eviten permanecer indolentes e impunes a ellos; mientras que Eduardo Liendro y Darío lbarra comparten la necesidad de contar con criterios y enmarques específicos en el trabajo con hombres que ejercen violencias, aún los facilitados en por programas reeducativos vinculados a servicios de seguridad pública o impartición de justicia, para que la impartición de justicia sea efectiva y contribuya de manera sustantiva a la transformación social.

En diversos análisis y críticas feministas, coincidimos en que la masculinidad hegemónica es el punto de partida de múltiples opresiones y subordinación, pero requerimos seguir profundizando en su funcionamiento, dinámicas e interrelación con los demás sistemas de opresión, sobre todo frente a una impartición de justicia masculinista que continúa a pesar de haber avanzado progresivamente en un marco de derechos humanos. Por ello, el debate propiciado por esta obra resulta necesario de profundizar en lo que a la justicia se refiere, así como de extenderlo al resto de nuestras estructuras sociales. 